\title{
"Tratando a água": Um jogo didático para o ensino de química com enfoque na abordagem Ciência, Tecnologia e Sociedade - CTS
}

\author{
"Treating water": A didactic game for teaching chemistry with a focus on the Science, Technology \\ and Society - STC approach \\ "Tratando el agua": Um juego didáctico para la enseñanza de la química con un enfoque de \\ Ciencia, Tecnología y Sociedad - CTS
}

Recebido: 24/03/2021 | Revisado: 30/03/2021 | Aceito: 03/04/2021 | Publicado:13/04/2021

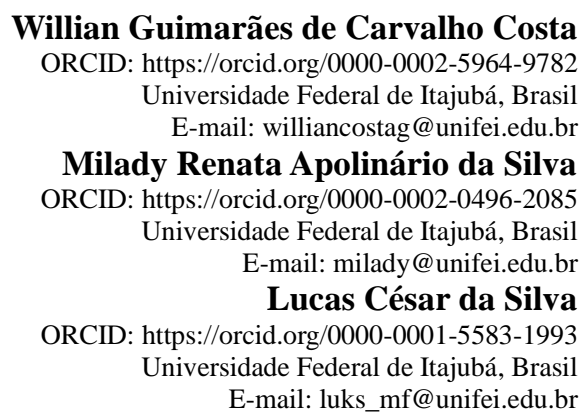

\begin{abstract}
Resumo
Em vista das dificuldades de se contextualizar os conteúdos trabalhados na disciplina de química com o cotidiano dos alunos para facilitar sua compreensão e tornar os processos de ensino e de aprendizagem mais efetivos, professores recorrem a variadas estratégias de ensino e recursos didáticos para dinamizarem suas aulas e despertar o interesse dos alunos. Sendo assim, este trabalho tem como objetivo a proposição de uma sequência didática (SD), com enfoque na abordagem Ciência, Tecnologia e Sociedade (CTS), utilizando um jogo como recurso didático, para serem utilizados por professores dos anos finais do Ensino Fundamental II e do Ensino Médio. A metodologia empregada foi a pesquisa qualitativa tendo os dados referentes às contribuições da utilização de recursos didáticos e da abordagem CTS presentes na SD, analisados buscando-se elementos que conferissem a sequência didática e ao jogo, um caráter CTS. Constatou-se que a abordagem CTS associada à utilização do jogo didático, contribui de forma significativa para o ensino de química, aproximando os alunos do conteúdo e motivando-os a construírem o conhecimento de forma lúdica e eficiente.
\end{abstract}

Palavras-chave: Educação ambiental; Saneamento básico; Tratamento de água; Separação de misturas.

\begin{abstract}
In view of the difficulties of contextualizing the contents worked in the subject of chemistry with the daily of students to facilitate their understanding and make the teaching and learning processes more effective, teachers resort to various teaching strategies and didactic resources to energize their classes and arouse the interest of students. Therefore, this work aims to propose a didactic sequence (DS), focusing on the Science, Technology and Society (STC) approach, using a game as a didactic resource, to be used by teachers in the final years of Elementary II and High School. The methodology used was qualitative research having the data regarding the contributions of the use of didactic resources and the STC approach present in the DS, analyzing elements that would confer to the didactic sequence and the game, a STC character. It was found that the STC approach associated with the use of the didactic game, contributes significantly to the teaching of chemistry, bringing students closer to the content and motivating them to build knowledge in a playful and efficient way.
\end{abstract}

Keywords: Environment education; Basic sanitation; Water treatment; Mixture separation.

\section{Resumen}

Ante la dificultad de contextualizar los contenidos trabajados en la disciplina de química con la vida cotidiana de los alumnos para facilitar su comprensión y hacer más efectivos los procesos de enseñanza y aprendizaje, los profesores recurren a diversas estrategias de enseñanza y recursos didácticos para agilizar sus clases y despertar el interés de los alumnos. Así, este trabajo tiene como objetivo proponer una secuencia didáctica (SD), centrada en el enfoque de Ciencia, Tecnología y Sociedad (CTS), utilizando un juego como recurso didáctico, para ser utilizado por los 
profesores de los últimos cursos de primaria II y de secundaria. La metodología utilizada fue la investigación cualitativa, y se analizaron los datos relativos a las aportaciones del uso de los recursos didácticos y el enfoque CTS presentes en el DS, buscando elementos que pudieran dar a la secuencia didáctica y al juego un carácter CTS. Se comprobó que el enfoque CTS asociado al uso del juego didáctico contribuye significativamente a la enseñanza de la química, acercando a los estudiantes al contenido y motivándolos a construir el conocimiento de manera lúdica y eficiente.

Palabras clave: Educación ambiental; Saneamiento básico; Tratamiento del agua; Separación de la mezcla.

\section{Introdução}

O ensino de química vem se desenvolvendo no mundo de maneira acentuada, acompanhando o progresso da tecnologia e da sociedade. Porém, também tem sido motivo de preocupação para professores e pesquisadores da área, devido às barreiras encontradas em sala de aula, para se construir o conhecimento científico e ao mesmo tempo torná-lo acessível e atraente para o público discente. Como apontado por Cardoso e Colinvaux (2000), em parte isso ocorre devido ao desinteresse dos alunos pelo conteúdo, que muitas vezes são desmotivados pela forma em que ele é trabalhado, tornando mais dificultosa a atividade do professor em sala de aula e trazendo pouca efetividade para o processo de ensino e aprendizagem.

Aqueles autores ressaltam ainda que em consequência de vivermos em sociedade, assumimos um conhecimento que se desenvolve continuamente, se tornando mais claro e estruturado devido ao fato de que sempre há discussão e reconstituição de nossas ideias com os outros. Em contrapartida, nem sempre a escola proporciona uma discussão entre os educandos em relação ao conhecimento construído, podendo isso ocorrer devido ao escasso tempo ou até mesmo a contradição entre o currículo e as práticas pedagógicas.

Na perspectiva de Pontes et al. (2008), em aulas de ciências, em especial aquelas em que se aborda os conteúdos de química, é notável a dificuldade dos estudantes em transpor os conceitos abordados para a sua realidade. Desta forma, acaba sendo dificultada a percepção da aplicação da função e da importância dos conteúdos em seu dia-a-dia e a relação destes com a sociedade como um todo.

De acordo com Trassi et al. (2001), esse fato tem sua origem a partir de um ensino tradicional, que não prioriza o processo de construção do conhecimento relativo ao aluno, e apenas realça a transmissão do conhecimento e a memorização de conteúdo. Nesse sentido, se faz presente o dever de tratar a educação química associando o ensino aos episódios corriqueiros na vida do aluno e assim, priorizar de forma contextualizada o desenvolvimento da construção do conhecimento (Trevisan \& Martins, 2006), de forma que fique clara para ele a importância dos conceitos químicos em uma sociedade avançada no sentido tecnológico como a que presenciamos nos dias atuais.

Para tal, tem-se como exemplo a abordagem Ciência Tecnologia e Sociedade - CTS, que segundo Ferreira et al. (2018, p. 250) ao discutirem as considerações abordadas por Santos e Mortimer (2002), afirmam que esta abordagem tem por objetivo a "formação de cidadãos a partir de uma alfabetização sociocientífica e tecnológica, tencionando tornar os discentes capazes de refletir de forma crítica a respeito dos rumos da sociedade".

Lima (2012) afirma que é fundamental que haja uma análise e discussão acerca da metodologia empregada pelos professores em suas aulas, com o intuito de identificar as dificuldades dos alunos em aprender química, e compreender o desinteresse deles para o estudo da disciplina. Além disso, para Silva, Almeida e Brito (2011, p.1) "a aprendizagem de Química deve possibilitar aos alunos a compreensão das transformações químicas que ocorrem no mundo físico de forma abrangente e integrada", pois assim eles poderão julgar as informações obtidas com fundamentos, tomar suas próprias decisões e se relacionarem com o mundo assumindo as posições de sujeito e de cidadão.

Como apontado por Andrade (2008), os professores não são considerados e nem acolhidos em suas carências pelas propostas curriculares desenvolvidas no Brasil. Com isto correlaciona-se o fato de que os professores de química, em sua 
generalidade, afirmam ter dificuldades para completar o conteúdo programático no tempo determinado, o que impossibilita a criação de novas atividades a serem desenvolvidas; atividades estas, que auxiliam a didática em sala de aula.

Diante deste contexto, apesar de ainda escassa entre os docentes da disciplina de química, a inovação em práticas pedagógicas associadas com a utilização de variadas metodologias e recursos didáticos como modelos, jogos, vídeos entre outros, se faz presente como uma tentativa de vencer este cenário, e enriquecer o processo de ensino aprendizagem. Como exemplo, Cunha (2012) aponta que a utilização de jogos, auxilia o aluno a desenvolver diferentes maneiras de pensar e confere ao professor um status de estimulador da aprendizagem.

Segundo Ferreira (2010), a elaboração de recursos didáticos adotados no ensino de ciências possibilita a conexão entre teoria e prática. As atividades práticas e os experimentos precisam ser guiados aspirando a objetivos distintos, como por exemplo demonstrar um fundamento teórico ou um fenômeno, estimular a aptidão para observação, entre outros, possibilitando o desenvolvimento do pensamento reflexivo do aluno.

Na concepção de Freitag (2017, p. 20), uma das etapas de grande importância quando se trata do processo de ensino e aprendizagem é a escolha dos recursos didáticos, pois os "recursos adequados podem representar instrumentos facilitadores capazes de estimular e enriquecer a vivência diária não só dos educadores, mas também dos educandos".

Silva (2017) ressalta que o uso de jogos educacionais pode beneficiar o aprendizado e despertar a motivação e interesse pelas aulas e pelos conteúdos, incentivando a participação, e fazendo com que o aluno construa seu conhecimento de forma divertida. Neste contexto, Perovano (2017) afirma que é necessário compreender que os jogos didáticos não comutam as outras estratégias de ensino, pois eles moldam-se como assistência para o professor e como influentes encorajadores para os educandos que aprendem por meio deles.

Sendo assim, pode-se dizer que os recursos didáticos são utilizados como um apoio para que o professor consiga contextuar os conceitos trabalhados e despertar no aluno a motivação em não só aprender o conteúdo, como também ser capaz de compreender sua colocação nas esferas da sociedade e ser capaz de aplicá-lo em resoluções de problemas; pois, "o aluno motivado busca novos conhecimentos e oportunidades, mostrando-se envolvido com o processo de aprendizagem, envolve-se nas tarefas com entusiasmo e demonstra disposição para novos desafios" (Alcará \& Guimarães, 2007, p. 177).

Lourenço e Paiva (2010, p. 133) pontuam que, "no contexto educacional, a motivação dos alunos é um importante desafio a ser enfrentado, pois tem implicações diretas na qualidade do envolvimento do aluno com o processo de ensino e aprendizagem". Por meio da motivação, o aluno passa a se interessar em descobrir novas oportunidades e construir novos conhecimentos, apresentando maior envoltura com o processo de aprendizagem.

Como discutido por Moran (2018), os jogos podem ser aplicados de forma individual ou coletiva e despertam o interesse do aluno através da ludicidade que envolve o conteúdo trabalhado a uma temática que motiva os estudantes; hoje, na sociedade globalizada, a utilização de jogos por crianças e adolescentes é extremamente comum, o que torna esta atividade mais prazerosa para eles e de fácil utilização pelo professor.

Considerando os pontos anteriormente apresentados, o presente trabalho tem por objetivo o desenvolvimento de um jogo para ser utilizado como recurso didático e a proposição de uma sequência didática - SD, desenvolvida com enfoque na abordagem Ciência Tecnologia e Sociedade - CTS, para trabalhar o Tratamento de Água, e ser utilizado por professores em aulas de química dos anos finais do Ensino Fundamental II e no primeiro ano do Ensino Médio; a SD e o jogo produzidos não foram aplicados em sala de aula, pois tratam-se de uma proposição.

\section{Metodologia}

O presente trabalho, constitui-se de uma pesquisa de caráter qualitativo, onde foram desenvolvidos uma sequência e um jogo didático, para serem utilizados por professores que objetivem trabalhar o conteúdo de Misturas e Métodos de 
Separação de misturas, nos anos finais do Ensino Fundamental II e no primeiro ano do Ensino Médio, por meio do tema tratamento de água.

De acordo com Batista (2016, p. 4), uma sequência didática "consiste em propostas metodológicas para a organização e planejamento do ensino, com diferentes aspectos e ênfases". O autor ressalta ainda que,

[...] uma sequência didática deve ser desenvolvida na perspectiva do ensino de conteúdos através de atividades sequenciadas, organizadas com objetivos bem definidos e esclarecidos para os professores e alunos, que contribuirão para a aprendizagem e construção do conhecimento e de novos saberes. Deve, também, servir para a reflexão sobre a prática docente através da observação do seu processo de desenvolvimento e interação entre todos os envolvidos. [...] uma sequência didática bem planejada permitirá ao educador visualizar o conhecimento inicial do aluno, seu desempenho e perceber o que ainda necessita ser trabalhado para que se concretize a aprendizagem (Batista, 2016, p. 4).

Sendo assim, foi desenvolvida uma sequência didática em que se organizou as ações a serem tomadas pelo professor, e descrevendo-se a melhor maneira de serem executadas para possibilitar a discussão dos temas propostos e para que os objetivos de ensino fossem cumpridos de forma eficaz.

Para a utilização do jogo como um recurso didático e sua inserção nos aspectos de ciência tecnologia e sociedade, foi escolhido o tema central Misturas, comumente abordado na disciplina de química; o tema foi escolhido devido a relação que pode ser estabelecida com o tratamento de água, processo empregado no dia a dia e de grande relevância, social, científica e tecnológica.

Como apontado por Rocha e Rodrigues (2018, p. 1) “o jogo didático deve ser utilizado como forma de simplificar ou até mesmo como um meio de associar o conteúdo trabalhado em sala de aula com algo mais 'palpável' e atrativo aos discentes." Sendo assim, o jogo intitulado "Tratando a água" foi desenvolvido contemplando perguntas de múltipla escolha acerca do conteúdo, e desafios que devem ser cumpridos pelos alunos para que a atividade se torne mais extrovertida e desperte a motivação dos mesmos.

O jogo desenvolvido trata-se de um quiz inspirado em um programa de televisão de nome "Passa ou repassa". A última fase trata-se de um esquema de uma estação de tratamento de água - ETA, que deve ser montada com as peças em ordem correta para garantir pontuação no jogo, que por sua vez foi inspirada em um jogo intitulado "Quebra-cabeça".

A sequência didática foi desenvolvida em quatro momentos, sendo que cada um deles foi tratado em uma aula de 50 minutos. Destes 50 minutos, foi reservado um tempo para a organização da classe, em que geralmente o professor chegava em sala de aula e realizava a chamada. As duas primeiras aulas tratando-se de uma introdução teórica dos conteúdos, a terceira aula a aplicação do jogo desenvolvido, e a última aula a avaliação.

A metodologia escolhida para as duas primeiras aulas foi a expositiva dialogada, que segundo Coimbra (2017) considera o contexto cultural dos alunos, suas realidades e suas experiências. Por meio desta metodologia, o professor pode auxiliar de maneira mais efetiva os alunos a analisar as informações, levantar características, comparar, interpretar e comentar; fazendo assim, com que a aula fique mais dinâmica contando com a participação da classe, sem deixar de lado o conteúdo a ser abordado.

Para o início das aulas foi escolhida a estratégia de brainstorming (tempestade de ideias), que segundo Xavier (2018, p. 9). "permite o levantamento das informações que os alunos já possuem acerca de um tema, com uma operacionalização relativamente simples". Por meio dela, os alunos podem ser questionados e ficarem livres para expor suas ideias prévias acerca do tema, sem que haja um diálogo em busca de uma resposta correta, e para que seja dada a devida importância à construção das respostas, ou seja, as experiências - sejam elas de senso comum ou conhecimento técnico - que eles trazem de sua própria 
vivência; para tal, foram elaboradas algumas perguntas que trazem características que levam os alunos a refletir sobre os aspectos iniciais da discussão posterior.

As duas primeiras aulas contam com a sessão "material de apoio", onde foram indicadas algumas sugestões para leitura em livro didático aprovado pelo Programa Nacional do Livro Didático do ano de 2018 (BRASIL, 2018), assim como vídeos e sites acadêmicos acerca dos conteúdos a serem tratados, que podem auxiliar o professor no direcionamento das discussões. Para avaliação das aulas, alocada na última aula da SD, foram propostas a avaliação diagnóstica por meio do brainstorming realizado nas aulas 1 e 2, em que o professor procura entender o que os alunos conhecem acerca do tema, estabelecendo um ponto de partida e tem a possibilidade de fazer correções acerca de conceitos equivocados; e a avaliação de verificação da aprendizagem ao final, através de um questionário elaborado, por meio do qual o professor verifica a aprendizagem dos conceitos trabalhados, e por meio dele pode identificar melhorias na forma de condução da atividade.

A SD apresenta o enfoque na perspectiva CTS, apoiada na compreensão de Santos e Mortimer (2002, p.1) que ao discutirem os pressupostos teóricos desta abordagem, afirmam que currículos com este enfoque, "apresentam como objetivo central preparar os alunos para o exercício da cidadania e caracterizam-se por uma abordagem dos conteúdos científicos no seu contexto social”, e também nas concepções de Santos e Belmiro (2013) que ao discutirem as contribuições da utilização de recursos didáticos em sala de aula, destaca que por meio deles, pode-se desenvolver a capacidade de observação, assim como aproximar o aluno da realidade e permitir uma aprendizagem de forma efetiva.

Para discutir os resultados obtidos por meio da análise das contribuições da utilização do jogo como recurso didático e da abordagem CTS presentes na SD, foi realizada uma análise crítica sobre os dados elaborados, buscando-se elementos presentes na SD e no jogo didático que conferissem a ambos um enfoque na abordagem Ciência, Tecnologia e Sociedade.

\section{Resultados e Discussão}

\subsection{Sequência e Jogo Didático}

Na Tabela 1, é apresentada a SD proposta, considerando os pressupostos teóricos apresentados e a metodologia selecionada para a pesquisa, para o ensino dos temas tratamento de água, misturas e métodos de separação de misturas de forma correlata.

Tabela 1 - Sequência Didática: As misturas e o tratamento de água.

\begin{tabular}{|c|c|}
\hline Tema & Misturas e processos de separação de misturas / Tratamento de água. \\
\hline $\begin{array}{l}\text { Nível } \\
\text { Ensino }\end{array}$ & Ensino Fundamental II (anos finais) e primeiro ano do Ensino Médio. \\
\hline $\begin{array}{l}\text { Duração } \\
\text { prevista }\end{array}$ & 4 aulas (50 minutos cada). \\
\hline \multirow[t]{2}{*}{ Objetivos } & $\begin{array}{l}\text { Conhecer e compreender os processos envolvidos no tratamento de água; assim como } \\
\text { tipos de misturas e processos de separação de misturas. }\end{array}$ \\
\hline & $\begin{array}{l}\text { Metodologia de Ensino: Expositiva dialogada. } \\
\text { Cronograma: Organização Da classe: } 5 \text { min. / Brainstorming: } 10 \text { min. / Introdução } \\
\text { teórica: } 35 \text { min. } \\
\text { Plano de Ação: } \\
\quad \text { No início da primeira aula o professor deve realizar um brainstorming, colocando aos } \\
\text { alunos os seguintes questionamentos: } \\
\text { 1- O que é uma substância? } \\
\text { 2- O que é uma mistura? } \\
\text { 3- Existem misturas sólidas? } \\
\text { 4- Quem pode dar exemplos de misturas? }\end{array}$ \\
\hline
\end{tabular}


Após o brainstorming o professor deve fazer uma introdução teórica acerca do conteúdo programático Misturas e Separação de Misturas; devem ser abordadas os conceitos de misturas homogêneas e heterogêneas, assim como os processos de separação de misturas por decantação e filtração.

Durante a primeira aula é importante fazer relações do conteúdo com misturas presentes no cotidiano dos alunos, e recomenda-se utilizar a lousa e giz para fazer modelos desenhados.

Ao tratar de misturas heterogêneas sugere-se citar água + óleo (oportunidade para comentar sobre vazamento de petróleo no mar e como se dá seu monitoramento) e realizar o questionamento de quantas fases é possível visualizar neste caso; ao tratar de misturas homogêneas, sugere-se citar água + sal (oportunidade para comentar acerca da água do mar, na qual não se observa o sal) e realizar o questionamento de quantas fases é possível visualizar, diferenciando assim do exemplo da água + óleo.

Para os processos de separação, sugere-se citar para a filtração, o preparo de café que é realizado em casa; para o processo de decantação sugere-se citar o preparo de sucos (onde o pó não dissolvido desce para o fundo do recipiente por ação da gravidade).

Recursos Didáticos: Lousa, giz, livro didático.

Material de apoio:

Livro didático: MACHADO, A. H.; MORTIMER, E. F. Química - Ensino Médio, volume 1. Manual do professor. Editora Ática Scipione. 2018. Disponível em: https://www.aticascipione.com.br/pnld/edital/pnld-2018/obra/1458001/ .

Khan Academy - Misturas e Separação de Misturas. Disponível em:

https://pt.khanacademy.org/science/6-ano/materia-e-energia-6-ano/separacaomisturas/a/separacao-de-misturas

Metodologia de Ensino: Expositiva dialogada.

Cronograma: Organização Da classe: 5 min. / Brainstorming: 10 min. / Introdução teórica: 35 min.

Plano de Ação:

No início da segunda aula o professor deve realizar um brainstorming, realizando os seguintes questionamentos:

1- De onde vem a água que utilizamos em nossas casas?

2- Como saber se a água é ou não, própria para consumo?

3- O que poderia acontecer se a água que utilizamos não fosse tratada?

4- Para onde vai a água depois que a utilizamos?

Posteriormente o professor deve realizar uma introdução teórica acerca do tratamento de água e como funciona uma ETA (Estação de Tratamento de Água). É importante salientar a fase de captação da água dos rios por meio de bombas e tubulações, assim como a distribuição pós tratamento, o monitoramento de represas, entre outros aspectos que abrem espaço para comentar acerca das contribuições da tecnologia para o processo.

O professor deve comentar sobre os processos de floculação (relacionar com o conceito de mistura heterogênea apresentado na aula 01) e decantação (relembrar o conceito de decantação discutido na aula 01), o processo de filtração (relembrar o conceito de filtração discutido na aula 01), o processo de desinfecção (relacionar com o conceito de mistura homogênea), o armazenamento e a distribuição da água.

Um aspecto relevante a ser comentado é acerca de como chegou-se ao tratamento da água existente nos dias atuais, o que ocorreu por meio do desenvolvimento da ciência e da tecnologia, que continuam em constante mudança. Se possível, recomenda-se mostrar aos alunos uma imagem representativa de uma ETA.

É importante procurar a participação da turma, pedindo que indiquem as fases das misturas e os processos de separação, previamente discutidos na aula 01; e realizando questionamentos que sejam capazes de promover reflexões sobre as atitudes muitas vezes tomadas pelos seres humanos, que demonstram a desvalorização deste recurso 


\begin{tabular}{|c|c|}
\hline & 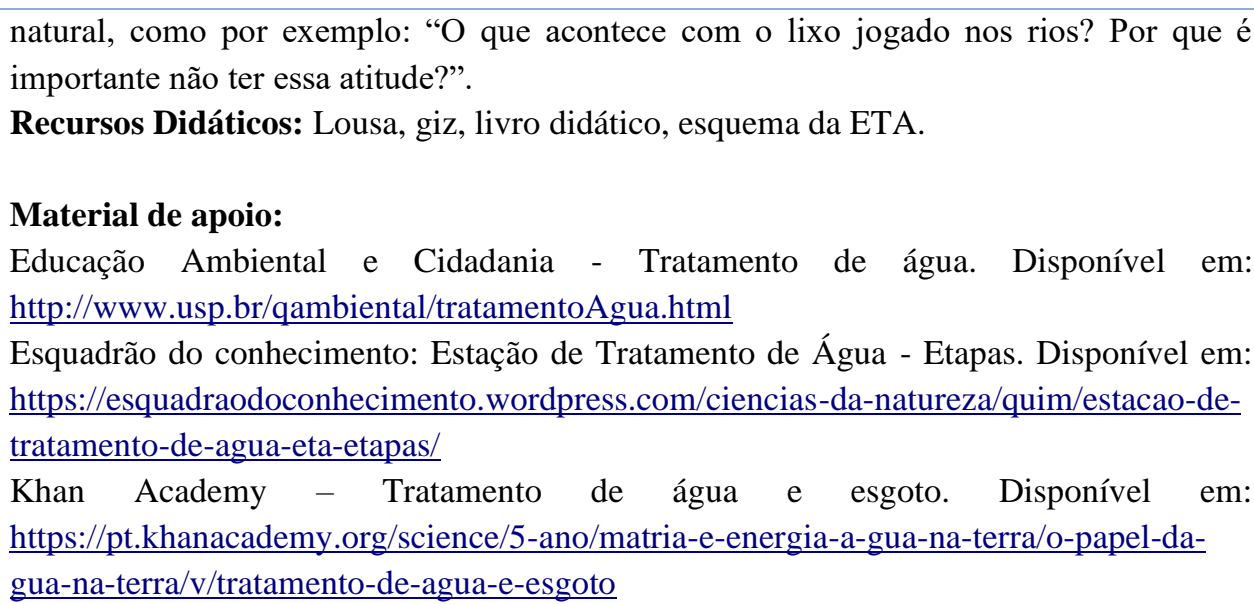 \\
\hline AULA 3 & $\begin{array}{l}\text { Metodologia de Ensino: Aplicação do jogo. } \\
\text { Cronograma: Organização Da classe: } 10 \text { min. / Aplicação do jogo: } 40 \text { min. } \\
\text { Plano de Ação: } \\
\text { No início da aula, o professor deve dividir a classe de alunos em dois grupos com o } \\
\text { mesmo número de integrantes, ou o mais aproximado possível. É interessante realizar na } \\
\text { sala de aula uma separação com as carteiras para delimitar o espaço onde cada grupo } \\
\text { deve se posicionar. } \\
\text { O jogo intitulado "Tratando a água" é composto por perguntas acerca do conteúdo } \\
\text { trabalhado nas aulas } 01 \text { e 02, e envolve questionamentos relacionados ao conteúdo } \\
\text { programático misturas e processos de separação de misturas assim como sobre o } \\
\text { tratamento de água. Além disso, o jogo conta com desafios para deixar a atividade mais } \\
\text { extrovertida e estimular a participação. } \\
\text { As perguntas devem ser respondidas por duplas de alunos das equipes fazendo um } \\
\text { rodízio para que o máximo de alunos possam participar; sendo assim, se o número de } \\
\text { alunos de cada grupo permitir, uma mesma dupla não pode responder mais de uma } \\
\text { pergunta, ou cumprir mais de um desafio. A última pergunta será composta por um } \\
\text { esquema de uma estação de tratamento de água onde os alunos deverão montar as fases } \\
\text { em ordem correta para pontuar. } \\
\text { As perguntas e as regras do jogo se encontram abaixo, na Tabela } 2 \text {, assim como o } \\
\text { esquema da estação de tratamento a ser utilizado para montagem. O professor deve } \\
\text { participar como mediador do jogo, interagindo assim com a classe. } \\
\text { Recursos Didáticos: Jogo didático. }\end{array}$ \\
\hline AULA 4 & $\begin{array}{l}\text { Metodologia de Ensino: Avaliação da aprendizagem. } \\
\text { Cronograma: Organização Da classe: } 10 \text { min. / Aplicação de questionário: } 40 \text { min. } \\
\text { Plano de Ação: } \\
\quad \text { Nesta sequência didática pode-se estabelecer critérios para a avaliação do } \\
\text { conhecimento construído pelos alunos. } \\
\text { Inicialmente, pode-se realizar por meio do Brainstorming, uma avaliação } \\
\text { diagnóstica, onde o professor/monitor pode reconhecer os conhecimentos prévios dos } \\
\text { alunos e estabelecer um ponto de partida, para avaliar posteriormente o que foi aprendido } \\
\text { pelos alunos. } \\
\text { Após as aulas e a aplicação do jogo pode-se realizar uma avaliação de verificação da } \\
\text { aprendizagem por meio de um questionário a ser respondido pelos alunos } \\
\text { individualmente. Na Tabela } 3 \text { encontra-se o questionário sugerido para tal, composto por } \\
\text { questões de múltipla escolha e dissertativas. }\end{array}$ \\
\hline
\end{tabular}

Fonte: Autores.

Na Tabela 1, é importante observar a descrição geral da SD, composta por tema, nível de ensino, duração prevista e objetivo, assim como a separação em seções das aulas propostas com as respectivas sugestões para aplicação. 
O jogo didático desenvolvido junto à SD, é apresentado na Tabela 2. O jogo foi desenvolvido considerando-se os conteúdos abordados na SD, contendo perguntas de múltipla escolha e desafios que devem ser cumpridos pelos alunos.

Tabela 2 - Jogo didático: Tratando a água.

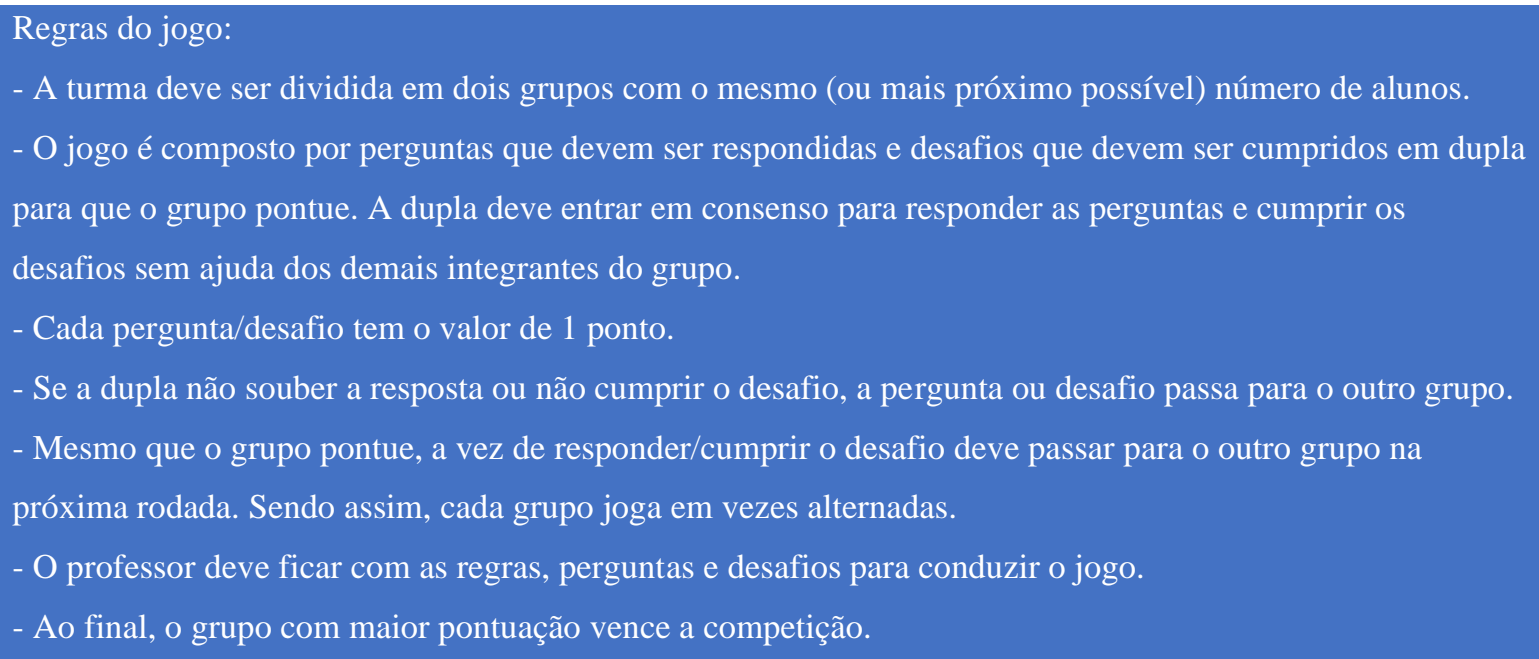

A) Para remover a sujeira com mais facilidade

B) Para não entupir a tubulação

C) Para descobrir quais substâncias estão presentes na água

4 - DESAFIO: Imite um macaco

5 - Na decantação o que acontece com a sujeira?

A) Afunda se depositando no fundo do recipiente

B) Boia se misturando na água

C) Boia até a superfície da água

6 - Para que serve a areia e o carvão do filtro de água? 

A) Para remover sais minerais
B) Para agrupar a sujeira
C) Para reter as partículas, possíveis odores e clarear a água

7 - DESAFIO: Pule num pé só enquanto canta uma música

8 - Porquê é realizada a adição de cloro na água?

A) Para eliminar microrganismos

B) Para dar cheiro a água

C) Para filtrar a água

9 - Qual a importância das bombas na distribuição da água?

A) Eliminar microrganismos da água

B) Limpar a água

C) Conferir pressão para que a água chegue em todas as casas

10 - DESAFIO: Faça uma mímica para seu grupo descobrir: BEBER.

11 - A água que utilizamos em casa é pura?

A) $\mathrm{Sim}$

B) Não, pois é uma mistura homogênea

C) Não, pois é uma mistura heterogênea

12 - A água que devolvemos para a natureza após lavar a louça é limpa?

A) Não pois pode conter contaminantes

B) Sim, pois o detergente não é contaminante

C) Sim, pois o detergente elimina microrganismos

13 - DESAFIO: Faça uma mímica para seu grupo descobrir: LIMPAR.

14 - A adição de flúor na água faz bem para:
A) Os ossos
B) Os dentes
C) A coluna

15 - O consumo de água não tratada pode acarretar em:
A) Doenças respiratórias
B) Contaminação devido a microrganismos
C) Infecção na garganta 
16 - DESAFIO: A dupla deve falar o título de um filme começado com a letra H.

17 - Pedro preparou um suco dissolvendo um pó na água. O pó não dissolvido pela água foi para o fundo da jarra. Qual o nome deste processo?
A) Dissolução
B) Mistura
C) Decantação

18 - DESAFIO: O professor deve anotar em um papel um número de 1 a 10 e a dupla têm que acertar qual é. Se não acertar passa para o outro grupo e assim sucessivamente até alguma dupla acertar.

19 - Monte as etapas da estação de tratamento de água corretamente.

\section{GABARITO}

\begin{tabular}{|c|c|c|c|c|c|c|c|c|c|c|c|c|}
\hline 1 & 2 & 3 & 5 & 6 & 8 & 9 & 11 & 12 & 14 & 15 & 16 & 17 \\
\hline B & B & A & A & C & A & C & B & A & B & B & $\begin{array}{l}\text { Sugestão: Harry Potter / High } \\
\text { School Musical }\end{array}$ & C \\
\hline
\end{tabular}

19 - Recomenda-se imprimir o esquema da Estação de tratamento, assim como as peças para montagem:

A ordem correta de montagem deve seguir a sequência de espaços disponíveis ligadas pelas gravuras de tubulações na seguinte ordem:

1 - Captação da Água

2 - Coagulação e Floculação

3 - Decantação

4 - Filtração

5 - Desinfecção

6 - Armazenamento

7 - Distribuição 
Research, Society and Development, v. 10, n. 4, e35210414237, 2021

(CC BY 4.0) | ISSN 2525-3409 | DOI: http://dx.doi.org/10.33448/rsd-v10i4.14237
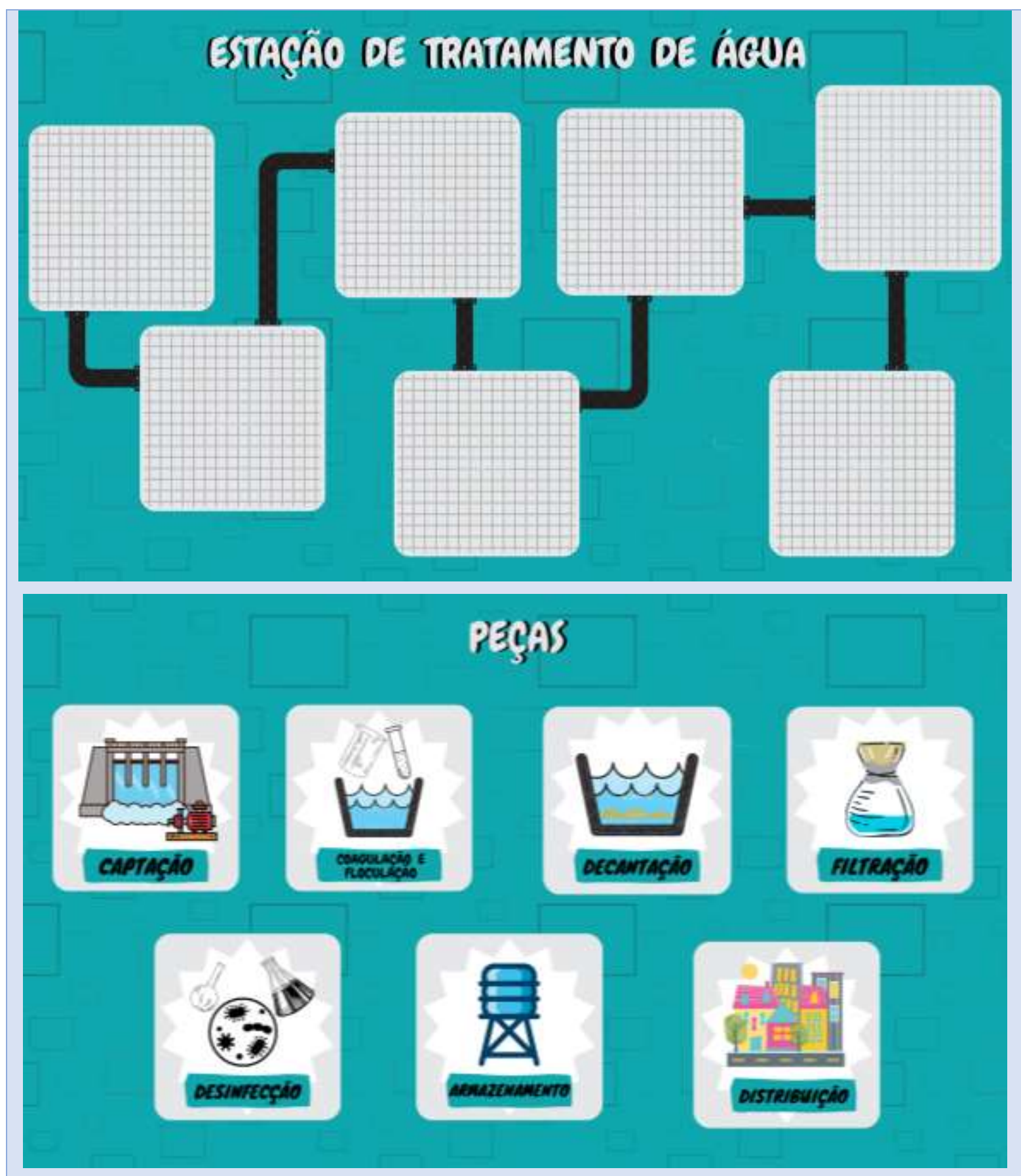

Fonte: Autores.

Na Tabela 2, é importante observar que no início estão dispostas as regras do jogo proposto, seguidas por suas perguntas e desafios constituintes; e além disto é disponibilizado o gabarito para conferência anterior à utilização.

Para avaliação da aprendizagem após o desenvolvimento da SD em sala de aula e a aplicação do jogo didático foi desenvolvido um questionário, que se encontra na Tabela 3. 
Tabela 3 - Questionário de avaliação.

1- O que é uma mistura?

2- Uma mistura homogênea é composta por:
a) Uma fase
b) Duas fases
c) Três fases
d) Uma substância

3- Açúcar dissolvido na água, pode ser classificado como uma mistura
a) Homogênea
b) Heterogênea

4- Se tivermos água, óleo e areia em um copo, podemos classificar esta mistura como:
a) Homogênea
b) Heterogênea

5- Para a separação de uma mistura de duas fases, sendo uma sólida e outra líquida, qual processo pode ser empregado?

6- Ao final do tratamento de água tem-se uma mistura do tipo:
a) Homogênea
b) Heterogênea

7- De que maneira a tecnologia auxilia no tratamento da água?

8- Se a água estiver muito poluída será necessário maior quantidade de reagentes para tratá-la? Justifique.
( ) SIM
( ) NÃO

9- Porque o tratamento de água é importante para a nossa saúde?

10- Explique sucintamente como é realizado o tratamento de água.

Fonte: Autores.

Na Tabela 3, é relevante se observar que as questões propostas estão relacionadas aos conceitos trabalhados tanto na SD quanto no jogo; caso julgue necessário, o professor pode fazer adaptações nas questões de acordo com o nível de ensino que estabeleça para sua(s) turma(s) de alunos.

\subsection{Contribuições da abordagem CTS presentes na SD}

O tema misturas e os processos de separação abordados na sequência didática, permitem elencar a abordagem CTS por meio da relação entre os fatores e da importância de cada um deles, para o tratamento da água que é um processo necessário e de grande importância para a saúde humana.

Podemos destacar os aspectos relativos à ciência por meio de toda a exemplificação das fases do tratamento em que são empregados reagentes químicos - como o processo de coagulação, desinfecção, correção de pH e fluoretação - que desempenham funções essenciais para que a água se torne própria para o consumo humano sem tantos riscos de causar danos à saúde. Também ao que se refere aos processos de separação da sujeira da água por decantação e por filtração, que são processos explicados por fatores científicos.

Por meio disto, destaca-se a importância e a responsabilidade da ciência no dia a dia dos alunos, e também a aproximação de como ela é utilizada para a melhoria da qualidade de vida; sendo assim, demonstra-se um cuidado de evitar superficialidade ao relacionar os conceitos científicos com o cotidiano, pois como apontado por Wartha et al. (2013, p. 85) a "[...] utilização de fatos do dia a dia para ensinar conteúdos científicos pode caracterizar o cotidiano em um papel secundário, ou seja, este servindo como mera exemplificação ou ilustração para ensinar conhecimentos químicos". 
Os aspectos relativos à tecnologia, podem ser encontrados na etapa de discussão acerca das fases de captação da água dos rios e distribuição para as residências da cidade por meio de tubulações, e bombas que conferem pressão a água fazendo com que seu alcance e velocidade de distribuição sejam ampliados, assim como equipamentos de monitoramento de represas, vazão de água, entre outros.

A tecnologia também pode ser elencada ao se tratar da estrutura da ETA como um todo, onde são necessários diferentes equipamentos tecnológicos para desempenharem funções que sem eles, seriam mais vagarosas e menos eficientes para atender uma alta demanda. Nas fases de decantação e filtração, relaciona-se tecnologia e ciência como fatores dependentes um do outro, a ciência para explicar os processos, como supracitado, e a tecnologia permitindo o desenvolvimento de estudos e pesquisas que tornam estes fatos possíveis.

Sendo assim, evidencia-se a tecnologia como aliada do ser humano e como ferramenta facilitadora de processos e que exige uma visão de desenvolvimento constante, capaz de adaptar e melhorar a qualidade de vida e o desenvolvimento de uma sociedade.

Santos e Mortimer (2002) discutem o eixo da sociedade como uma oportunidade viável de se mostrar aos alunos suas responsabilidades enquanto cidadãos e os valores humanos que são fundamentais para a boa utilização da ciência e da tecnologia. Tratando do aspecto sociedade, podemos destacar na sequência didática a discussão proposta para ser realizada durante a aula sobre o tratamento da água, discussão essa, relativa ao lixo jogado nos rios. Por meio disso procura-se conscientizar os alunos acerca dos valores da sociedade como um todo, valores estes, relativos ao cuidado com o meio ambiente e com o recurso natural fundamental para a sobrevivência humana.

Sendo assim, a sequência didática proposta dá a oportunidade para o professor trabalhar os aspectos do cotidiano dos alunos e da sociedade a sua volta, e integrá-los ao conhecimento científico sem estabelecer uma relação que seja tida como artificial (Santos \& Mortimer, 2002), pois o tratamento da água se discute um processo comumente empregado e também aborda problemas reais, muitas vezes sendo passado despercebido pelas pessoas e como citado por Bouzon (2018, p.2) a abordagem CTS trata-se de "uma abordagem que busca superar esse quadro e que se preocupa em ampliar o processo de ensino-aprendizagem para além dos muros da escola".

Santos e Mortimer (2002, p. 6), discutem ainda que "os processos de investigação científica e tecnológica propiciariam a participação ativa dos alunos na obtenção de informações, solução de problemas e tomada de decisão", portanto, o tema tratamento de água envolvendo o conteúdo misturas abordado na disciplina de química, proporciona a autonomia para que os alunos desenvolvam tanto suas habilidades acadêmicas em relação a ciência e a tecnologia, quanto suas habilidades e valores humanos, gerando a conscientização acerca de atitudes para com o ambiente.

\subsection{O jogo como recurso didático}

Conforme discutido por Santos e Belmiro (2013), ao utilizar um recurso didático em sala de aula, o docente transporta os conhecimentos teóricos do livro didático para o cotidiano do aluno; portanto, a utilização do jogo de perguntas como um recurso didático, tem o potencial de aproximar a ciência e a tecnologia envolvidas no processo do tratamento de água de sua realidade e ao mesmo tempo seguir com o conteúdo relativo às misturas e os métodos de separação, que devem ser aprendidos na disciplina química e que são de extrema importância para o desenvolvimento do aluno como cidadão e profissional.

O jogo desenvolvido apresenta potencialidade como recurso didático, a última etapa de montagem da ETA que cria uma possibilidade dos alunos visualizarem a estrutura da mesma, mesmo que por meio de um modelo; Santos \& Belmiro (2013) discutem essa potencialidade de visualização ao afirmar que os recursos didáticos são atrativos para que os alunos possam além da forma textual, compreender o conteúdo de forma mais dinâmica, pois proporcionam maior envolvimento com as informações apresentadas, garantido assim o seu sucesso. 
Santos e Belmiro (2013) apresentam outro ponto importante dos recursos didáticos, o de despertar a curiosidade, a capacidade de observação, de questionamento e a busca pela participação nas atividades. Isso pode ser observado na proposta do jogo por ele se constituir de perguntas relacionadas aos conteúdos trabalhados nas duas primeiras aulas da SD e também por se tratar de uma competição entre dois grupos de alunos, o que desencadeia maior envolvimento da turma e leva os alunos a pensarem e discutirem criticamente antes de dar uma resposta final.

É importante ressaltar ainda que, como discutido por Santos \& Belmiro (2013) cada recurso didático utilizado provoca um impacto sobre os alunos e consequentemente sobre a forma com que assimilam o conteúdo, portanto é importante que o professor avalie previamente em seu planejamento se o recurso a ser utilizado se emprega de forma eficaz no planejamento de sua aula.

Sendo assim, considera-se o jogo desenvolvido um recurso didático com diversas potencialidades, como as discutidas acima, por se tratar de um elemento que proporciona aos alunos além da visualização que aproxima o conteúdo trabalhado da realidade dos mesmos, a oportunidade de maior interação, fazendo com que eles se sintam mais motivados e mais instigados a questionar e compreender os aspectos científico-tecnológicos envolvidos no processo de tratamento da água e por meio disto, desenvolver a capacidade de tomada de decisão em relação a como valorizar e preservar este recurso, assim como acerca da utilização responsável e consciente da ciência e tecnologia.

\section{Considerações Finais}

Uma visita técnica a uma ETA, muitas vezes exige burocracia devido a normas de segurança, e para uma classe escolar pode se apresentar inviável por questões, como por exemplo, o custo e o tempo do deslocamento, alimentação dos alunos, questões relativas à segurança, entre outros. Portanto, o fato de trazer o processo de tratamento de água para os alunos para dentro da sala de aula, se dá como uma ação de promoção do incentivo ao estudo da disciplina de química. Todavia, é importante ressaltar que a visita técnica também possui suas potencialidades como estratégia de ensino e a SD e jogo desenvolvidos podem ser utilizados para aulas complementares após a realização de uma visita técnica a uma ETA.

O processo de tratamento de água trabalhado em sala de aula, traz a conscientização acerca da relação entre ciência tecnologia e sociedade por meio da premissa de que existem profissionais trabalhando continuamente para a melhoria da qualidade da água, que chega às residências e é consumida diariamente; reforça também o papel da ciência na vida das pessoas e como a sua investigação e evolução contribuem para a manutenção de uma vida saudável. Além disso, vale destacar que trabalhar temas referentes a água em sala de aula, sobretudo nas disciplinas de ciências, possibilita que o professor auxilie os alunos na construção de valores essenciais para o mundo em que vivemos atualmente; valores estes como a consciência da importância da preservação da natureza e de seus recursos.

Sendo assim, utilizar o tratamento de água como foco central para tratar do tema de misturas e seus processos de separação sob uma perspectiva que relaciona ciência, tecnologia e sociedade se dá como uma oportunidade de auxiliar os alunos a construírem o conhecimento de forma crítica, buscar alternativas para resolução de problemas, e reconhecer os fatores científicos e tecnológicos presentes no cotidiano; além de proporcionar a motivação para o estudo da disciplina de química, que muitas vezes é tida como uma matéria de difícil compreensão.

A organização de conteúdos em uma ordem que direcione a discussão abordada pelo professor em sala de aula em uma SD, se dá como uma etapa de grande relevância para o processo de ensino e aprendizagem, pois por meio dela o professor pode selecionar as ações a serem tomadas e que melhor cabem no contexto de cada sala de aula. Planejar qual, e como abordar o conteúdo programático é fundamental para que o professor se prepare técnica e emocionalmente para sua aula, o que lhe dá maior confiança e melhor preparo para responder possíveis dúvidas que venham a surgir, fazendo assim que o processo de aprendizagem dos alunos seja efetivo. 
O planejamento e a construção de uma SD também é importante para que os alunos direcionem a construção de seus conhecimentos em uma ordem que faça sentido; por exemplo, não seria viável abordar o tratamento de água sem que os alunos reconhecessem a decantação como um método de separação de misturas, pois isso demandaria um maior tempo para que o professor pudesse explicar tal conteúdo de forma clara e também poderia gerar uma confusão aos alunos, fazendo com que sua aprendizagem fosse defasada.

Quanto a utilização do jogo desenvolvido como um recurso didático, espera-se que seja proveitosa e relevante, pois diversifica a aula, fugindo de um modelo tradicional muitas vezes seguido por professores e que acaba criando certa resistência nos alunos.

Por meio da ludicidade é possível trabalhar os conteúdos teóricos necessários para a construção do conhecimento científico-tecnológico, aproximando os alunos da realidade e preparando-os para a resolução de problemas, assim como desenvolver seu senso crítico, e a capacidade de trabalhar em equipe. Sendo assim, utilizar jogos didáticos em sala de aula é uma ação que dá ao professor uma maior gama de possibilidades fazendo com que o processo de ensino e aprendizagem se torne mais flexível e dinâmico, sem perder sua eficácia. Este trabalho será disponibilizado e divulgado, para que professores e monitores de química possam utilizar a SD e o jogo para ministrarem o conteúdo de misturas, relacionando-o com os processos envolvidos no tratamento, de uma maneira lúdica e que foge a um modelo de ensino tradicional.

Para trabalhos futuros, sugere-se a análise dos aspectos relativos a Ciência, Tecnologia e Sociedade apresentados neste trabalho, e recomenda-se que a partir de tal análise desenvolva-se novas relações destes, com temas associados ao tratamento de água (como por exemplo o tratamento de esgoto) e à questões relativas a sustentabilidade, que devem ser iniciadas e posteriormente levadas para além dos muros da escola, sob uma perspectiva de que o homem por sua capacidade racional, deve zelar pela preservação do ecossistema em que vivemos.

\section{Referências}

Alcará, A. R. \& Guimarães, S. E. R. (2007). A instrumentalidade como uma estratégia motivacional. Associação Brasileira de Psicologia Escolar e Educacional (ABRAPEE), 11(1), 177-8.

Andrade, M. G. (2008). Planejamento e Plano de Ensino de Química para o Ensino Médio: concepções e práticas de professores em formação contínua. Dissertação (Mestrado). 276 f. Universidade de São Paulo. <https://www.teses.usp.br/teses/disponiveis/81/81132/tde-30082018152143/publico/Marcela_Gaeta_de_Andrade.pdf>.

Batista, R. C. (2016). Sequência didática - ponderações teórico-metodológicas. Mato Grosso. Anais XVIII ENDIPE - Encontro Nacional de Didática e Práticas de Ensino. 6 p. 〈https://www.ufmt.br/endipe2016/downloads/233_9937_37285.pdf〉.

Brasil. (2018). Ministério da Educação. Guia de livros didáticos PNLD 2018: Química. Ministério da Educação. MEC. <https://www.fnde.gov.br/pnld-2018/>.

Bouzon, J. D., Brandão, J. B., Santos, T. C. \& Chrispino, A. (2019). A química verde no ensino médio a partir da abordagem CTS. XII ENPEC - XII Encontro Nacional de Pesquisa em Educação em Ciências Universidade Federal do Rio Grande do Norte. <R1103-1.pdf (abrapecnet.org.br)>.

Cardoso, S. P. \& Colinvaux, D. (2000). Explorando a motivação para estudar química. Química Nova, 23(2), 401-404. $<$ http://www.scielo.br/pdf/qn/v23n3/2827.pdf >.

Coimbra, C. L. (2017). A aula expositiva dialogada em uma perspectiva Freiriana. Universidade Federal de Uberlândia/UFU. Eixo 07: Formação e desenvolvimento profissional de professores do ensino superior. <http://200.145.6.217/proceedings_arquivos/ArtigosCongressoEducadores/6495.pdf>

Cunha, M. B. (2012). Jogos no ensino de química: Considerações teóricas para sua utilização em sala de aula. Rev. Química Nova na Escola. 34(2), 92- 98. < http://qnesc.sbq.org.br/online/qnesc34_2/07-PE-53-11.pdf >.

Ferreira, L. H., Hartwig, D. R. \& Oliveira, R.C. (2010). Ensino experimental de química: uma abordagem investigativa contextualizada. Química Nova na Escola. 32(2), 101-106, <http://qnesc.sbq.org.br/online/qnesc32_2/08-PE-5207.pdf>.

Ferreira, W. M., Rocha, L. B., Santos, B. L. S. R., Santos, L. D., \& Pitanga, A. F. (2018) Corantes: uma abordagem com enfoque ciência, tecnologia e sociedade (CTS) usando processos oxidativos avançados. Química Nova na Escola. 40(4). 249-257. <http://qnesc.sbq.org.br/online/qnesc40_4/05-RSA-3617.pdf $>$.

Lima, J. O. G. (2012). Perspectivas de novas metodologias no Ensino de Química. Revista Espaço acadêmico. 12 (136). <http://www.educadores.diaadia.pr.gov.br/arquivos/File/setembro2013/quimica_artigos/perspect_novas_metod_ens_quim.pdf >. 
Research, Society and Development, v. 10, n. 4, e35210414237, 2021

(CC BY 4.0) | ISSN 2525-3409 | DOI: http://dx.doi.org/10.33448/rsd-v10i4.14237

Lourenço, A. A. \& Paiva, M. O. A. (2010). A motivação escolar e o processo de aprendizagem. Ciências \& Cognição.15 (2). 132-14. < http://pepsic.bvsalud.org/pdf/cc/v15n2/v15n2a12.pdf >.

Moran, J. (2018). Metodologias ativas para uma aprendizagem mais profunda. In: Bacich, L., Moran, J. (org.). Metodologias ativas para uma educação inovadora: uma abordagem teórico-prática. (p. 1-25).

Perovano, L. P., Pontara, A. B., \& Mendes, A. N. F. (2017). Dominó inorgânico: Uma forma inclusiva e lúdica para ensino de química. Revista Conhecimento Online. 2. 37-50. <https://periodicos.feevale.br/seer/index.php/revistaconhecimentoonline/article/vi ew/1088/1831>. ISSN $2176-8501$.

Pontes, A. N., Serrão, C. R. G., Freitas, C. K. A. F., Santos, D. C. P., \& Batalha, S. S. A. (2008). O ensino de química no nível médio: Um olhar a respeito da motivação. In: XIV Encontro Nacional de Ensino de Química - XIV ENEQ. Anais. 〈http://bohr.quimica.ufpr.br/eduquim/eneq2008/resumos/R0428-1.pdf >.

Rocha, D. F. \& Rodrigues, M. S. (2018). Jogo didático como facilitador para o ensino de biologia no ensino médio. Revista Cippus - Unilasalle. 8(2). (1-8). $\langle$ https://revistas.unilasalle.edu.br/index.php/Cippus/article/viewFile/4742/pdf >.

Santos, O. K. C., \& Belmiro, J. F. B. (2013). Recursos didáticos: uma melhoria na qualidade da aprendizagem. Editora Realize. (1-12). $\langle$ https://www.oeducador.com/download.php?arquivo=44940Texto_3.pdf >.

Santos, W. L. P., \& Mortimer, E. F. (2002). Uma análise de pressupostos teóricos da abordagem CTS no contexto da educação brasileira. Ensaio: Pesquisa em Educação em Ciências. 2(2). (110-132). <http://www.scielo.br/pdf/epec/v2n2/1983-2117-epec-2-02-00110.pdf >.

Silva, N.C (IFMA), Almeida, A. C. B. (IFMA) \& Brito, A. C. F. (IFMA). (2011). Dificuldade em aprender Química: uma questão a ser abordada no processo de ensino. In.: $51^{\circ}$ Congresso Brasileiro de Química, São Luís - MA. $<51^{\circ} \mathrm{CBQ}$ - Dificuldade em aprender Química: uma questão a ser abordada no processo de ensino (abq.org.br) >.

Silva, R. L. J. \& Strieder, R. B. (2017). A falta de água no bairro: educação CTS com alunos de $9^{\circ}$ ano do ensino fundamental. XI Encontro Nacional de Pesquisa em Educação em Ciências - XI ENPEC Universidade Federal de Santa Catarina, <http://www.abrapecnet.org.br/enpec/xienpec/anais/resumos/R1045-1.pdf>.

Trassi, R. C. M., Castellani, A. M., Gonçalves, J. E. \& Toledo, E. A. (2001). Tabela periódica interativa: "um estímulo à compreensão". Acta Scientiarum. 23(6). (1335-1339). 〈http://periodicos.uem.br/ojs/index.php/ActaSciTechnol/article/view/2757/1824>.

Trevisan, T. S., \& Martins, P. L. O. (2006). A prática pedagógica do professor de química: possibilidades e limites. UNIrevista. 1(2). <https://www.yumpu.com/pt/document/read/13056020/a-pratica-pedagogica-do-professor-de-quimica-possibilidades-e-limites/2〉.

Xavier, T. C. (2018). Relatório de Estágio de Mestrado em Ensino de Geografia no $3^{\circ}$ ciclo do ensino básico e no ensino secundário. Faculdade de Ciências Sociais e Humanas - Universidade Nova de Lisboa. 〈https://run.unl.pt/bitstream/10362/57501/1/relatorio_ver_final_thiagoxavier_ens_de_geografia.pdf >.

Wartha, J. E., Silva, L. E., \& Bejarano, N. R. (2003). Cotidiano e contextualização no ensino de química. Química Nova na Escola. 35(2). (84-91). <http://qnesc.sbq.org.br/online/qnesc35_2/04-CCD-151-12.pdf>. 